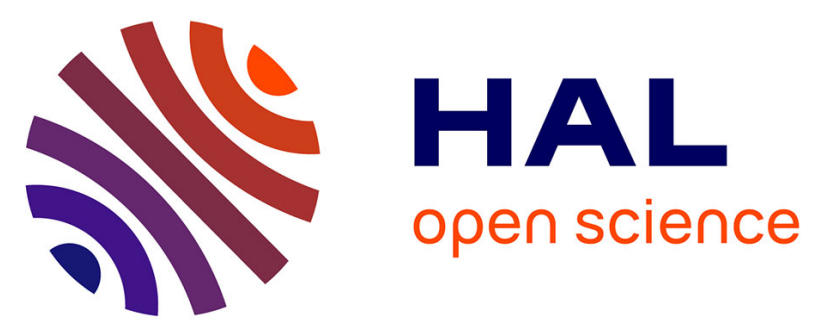

\title{
Deficient maturation of aspects of attention and executive functions in early onset schizophrenia
}

Jens Richardt M. Jepsen, Birgitte Fagerlund, Anne Katrine Pagsberg, Anne

Marie R. Christensen, Merete Nordentoft, Erik L. Mortensen

\section{- To cite this version:}

Jens Richardt M. Jepsen, Birgitte Fagerlund, Anne Katrine Pagsberg, Anne Marie R. Christensen, Merete Nordentoft, et al.. Deficient maturation of aspects of attention and executive functions in early onset schizophrenia. European Child and Adolescent Psychiatry, 2010, 19 (10), pp.773-786. 10.1007/s00787-010-0126-4 . hal-00612826

\section{HAL Id: hal-00612826 \\ https://hal.science/hal-00612826}

Submitted on 1 Aug 2011

HAL is a multi-disciplinary open access archive for the deposit and dissemination of scientific research documents, whether they are published or not. The documents may come from teaching and research institutions in France or abroad, or from public or private research centers.
L'archive ouverte pluridisciplinaire HAL, est destinée au dépôt et à la diffusion de documents scientifiques de niveau recherche, publiés ou non, émanant des établissements d'enseignement et de recherche français ou étrangers, des laboratoires publics ou privés. 
Title

Deficient Maturation of Aspects of Attention and Executive Functions in Early-Onset

Schizophrenia

\section{Column title}

\section{Cognitive Development in Early-Onset Schizophrenia}

Jens Richardt M. Jepsen ${ }^{1}(匹)$

Birgitte Fagerlund ${ }^{2}$

Anne Katrine Pagsberg ${ }^{1}$

Anne Marie R. Christensen ${ }^{1}$

Merete Nordentoft ${ }^{3}$

Erik L. Mortensen ${ }^{4}$

${ }^{1}$ Child and Adolescent Psychiatric Centre Bispebjerg

Copenhagen University Hospital Bispebjerg

Bispebjerg Bakke 23

2400 Copenhagen NV

Denmark

Telephone: +4535313531

Fax: +45 35316751

E-mail address: jrj01@ bbh.regionh.dk 
${ }^{2}$ Lundbeck Foundation Centre for Clinical Intervention and Neuropsychiatric Schizophrenia

Research

Psychiatric Centre Glostrup

Copenhagen University Hospital Glostrup

Nordre Ringvej 29-67

2600 Glostrup

Denmark

${ }^{3}$ Psychiatric Centre Bispebjerg

Copenhagen University Hospital Bispebjerg

Bispebjerg Bakke 23

2400 Copenhagen NV

Denmark

${ }^{4}$ Institute of Public Health and Center for Healthy Aging, University of Copenhagen

Øster Farimagsgade 5, opg. Z 1.sal

1014 Copenhagen $\mathrm{K}$

Denmark

Word count of the Abstract: 220

Word count of the text body: 5819 including the revised Appendix A 


\begin{abstract}
The few existing long-term, neuropsychological follow-up studies of early-onset schizophrenia (EOS) patients have reported relative stability in some cognitive functions but abnormal developmental trajectories in verbal memory, set shifting, aspects of attention, and speed of information processing throughout late adolescence into early adulthood. The current 5-year followup study compared the development of specific cognitive functions in EOS patients $(\mathrm{N}=17)$ from the time of first-episode to chronic phase with that of healthy controls $(\mathrm{N}=38)$ and secondarily to patients with other early-onset, non-organic, non-affective psychoses (EOP) (N=11). Speed of processing of executive functions, set shifting, and attention improved significantly in the healthy controls and reflected continuous functional maturation during late adolescence and early adulthood. The developmental progression of attention and set shifting but not speed of processing of executive functions was significantly subnormal in EOS patients. Other specific cognitive functions that had attained functional maturity in the healthy controls around the time of the baseline assessment showed normal development in EOS patients during the follow-up period, indicating stable cognitive deficits. These results suggest post-onset developmental deficits in two out of the three aspects of attention and executive functions that have protracted maturational trajectories and that overlap the age of onset of EOS. No significant difference in the development of any specific cognitive function was found between the EOS and EOP group.
\end{abstract}

\title{
Key words
}

Cognition, longitudinal, adolescent, early-onset psychosis, schizophrenia 


\section{Introduction}

It has been estimated that approximately $4 \%$ of all schizophrenia patients have their illness onset before 18 years of age [14], which is termed early-onset schizophrenia (EOS) [84]. Childhood-onset of schizophrenia (COS, onset by age 12) [39] is extremely rare [12;80], whereas the incidence increases between the ages 13 to 17 years [70;80]. A study including COS, also termed very earlyonset schizophrenia [39], observed cognitive deficits of comparable severity to those of patients with onset of schizophrenia between the ages of 13 and 18 years [71], and consequently, no distinction is made between COS and EOS patients in this paper. Previous controlled studies of EOS patients and adolescent patients with schizophrenia spectrum disorders have reported significant deficits in several specific cognitive functions such as speed of processing, attention, verbal memory, aspects of executive functions including mental flexibility and working memory, etc. $[6 ; 22 ; 29 ; 36 ; 44-46 ; 63 ; 71 ; 81 ; 85]$. Significant intelligence impairments have also been found in these clinical groups $[22 ; 29 ; 36 ; 46 ; 63 ; 71 ; 81 ; 81 ; 85]$. A few of these studies included patients with illness onset at the age of 18 years.

Only very few prospective longitudinal studies have assessed a possible change in the severity of intelligence impairments and specific cognitive deficits over time in EOS. A decline in intelligence, as reflected in deterioration in age-adjusted full scale intelligence quotient (FSIQ), has been observed around the time of illness onset in COS patients [27]. Similarly, post-onset IQs deteriorated relative to premorbid levels in a study of EOS patients with premorbid mental retardation (MR) [49]. Long-term stability in FSIQ has been observed in EOS patients [24;27]. However, a significant decline in FSIQ has been reported over a shorter time interval in COS patients [9]. Administering the same version of a Wechsler intelligence test and using the same baseline norms at baseline and after 5 years, our group previously found that FSIQ improvement 
was significantly smaller in EOS patients than in healthy controls, which suggested an abnormally slow acquisition of new intellectual information and skills during the first years after full clinical presentation [41]. In continuation of these results on intelligence development, the focus of our current study is on the development of specific cognitive functions in EOS. Frangou et al. (2008) reported a significant deterioration in immediate verbal memory and attention during the late adolescent years in EOS patients, while the performance in healthy controls improved. No differential change in the planning aspect of executive functions (EF) was observed, whereas information processing speed improved in EOS but not in controls [24]. In an impressive 13 year follow-up study, a significant decline in verbal memory and a lack of improvement in speed of information processing and the set shifting aspect of EF have also been found in EOS patients as opposed to stability and improvement among healthy controls [64]. Finally, a significant deterioration in executive attention has been found in EOS patients, while the performance in healthy controls remained stable [62].

EF are mental control processes that for example enable self-control necessary for the attainment of a future goal [20]. Contemporary theory suggest there are no unitary EF [26;78] but separable and related subprocesses [57]. Several definitions of EF and possible subprocesses exist [42]. The primary objective of the current study was to assess the development of different aspects of EF (set shifting, planning, working memory, speed of processing of EF) and other specific cognitive functions (attention, reaction time, motor speed, verbal memory) in first-episode EOS patients.

The development in EOS patients from the time of their first episode to 5 years post onset was primarily compared with that of healthy controls. We hypothesized that verbal memory would deteriorate in EOS patients but not in healthy controls. In addition, we expected subnormal growth 
in set shifting, reaction time, and attention in EOS patients. Finally, we hypothesized a relatively stable development in planning, working memory, speed of processing of EF, and motor speed in EOS patients.

The development in EOS patients during the 5 year follow-up period was secondarily compared to that of patients who at baseline had been diagnosed with other non-organic, non-affective psychoses in order to evaluate the specificity of a possible abnormal cognitive development in EOS patients. Compared to schizophrenia, the psychotic disorders included in the group of other non-organic, non-affective psychoses at baseline (see Appendix A) are, according to the ICD-10 [86] criteria, characterized by fewer, less specific psychotic symptoms or of a relatively short duration. In addition, preliminary analyses found some specific cognitive deficits at baseline to be substantially but not significantly smaller in the group of other non-organic, non-affective psychotic disorders than in the EOS group (see Figure 2). Thus, we hypothesized that these disorders, as a group, might be associated with less abnormal cognitive development than EOS during the follow-up period.

\section{Methods}

Sample

Forty eight patients, who met the ICD-10 [86] criteria for a first-episode, non-organic, psychotic disorder or schizotypal disorder, were recruited at baseline. Patients were between 10 and 17 years of age (both inclusive) at the time of their first contact with child- and adolescent psychiatric departments in the Copenhagen and Northern Zealand catchment areas in Denmark. The patient exclusion criteria were fulfilment of the ICD-10 diagnostic criteria for psychotic disorder due to psychoactive substance use (F1x.5), antipsychotic treatment for more than 6 months, the presence of any chronic somatic disease, severe head injury, neurological illness, compulsory hospitalization, 
or a premorbid diagnosis of mental retardation [71;89]. Patients and their parents were informed about the follow-up study and gave informed consent to be contacted for a follow-up assessment. The present analyses includes comparisons between 17 EOS patients and 11 patients with other early-onset, non-organic, non-affective psychoses (EOP) as diagnosed at baseline. Appendix A presents the baseline diagnostic distributions of these subgroups. The patients diagnosed with affective psychoses and schizotypal disorder at baseline, were excluded. Three EOS patients were antipsychotic naïve at the baseline neuropsychological assessment while the remaining 14 patients $(82 \%)$ had been treated with various first and second generation antipsychotic medications with a mean treatment duration of 8.3 weeks $(S D=6.1)$ (see Table 1). At baseline, 6 of the 11 patients with EOP $(55 \%)$ were treated with various first and second generation antipsychotic medications with a mean treatment duration of 6.2 weeks $(\mathrm{SD}=6.0)$; one EOP patient received additional anticholinergic treatment which may impair cognition [77]. As shown in Table 1, the EOS and the healthy control groups did not differ regarding mean age at baseline or follow-up, length of followup interval, number of years of education, or gender distribution, but parental baseline income and education/occupation differed significantly between the two groups. No significant differences were observed between the EOS and EOP groups in educational and sociodemographic characteristics at baseline (see Table 1). In addition, no significant difference in age of onset of psychotic symptoms, duration of untreated psychosis, baseline psychoticism, disorganization, or negative symptom dimension severity was found between the EOS and EOP groups. Since the time of the first clinical presentation, patients in both clinical groups received standard treatment (which did not include cognitive training).

Fifty three percent of EOS patients and $18 \%$ of EOP patients reported being treated with antipsychotic medications at the time of the follow-up assessment (see Table 1). Two EOS patients received additional anticholinergic treatment at follow-up, but their cognitive performance did not 
differ substantially from the remaining EOS patients and they were consequently included in all analyses.

Two EOS patients were diagnosed with co-morbid mental retardation at baseline in spite of the fact that intelligence deficits had not been recognized at the time of inclusion in the study. Additionally, three EOS patients were diagnosed with co-morbid SUD at baseline, 2 of whom also had co-morbid SUD at follow-up. No EOP patients suffered SUD at baseline but 2 EOP patients were diagnosed with SUD at follow-up.

\section{Figure 1 here}

At baseline, 46 healthy controls were recruited from schools and institutions in Copenhagen and matched with the patients on gender and age (within 6 months). Exclusion criteria for control subjects were a history of psychiatric disorders, learning disability, mental retardation, chronic somatic or head injuries, neurological disease, abuse of psychoactive substances, or a psychotic disorder in any first-degree relatives. Figure 1 shows the retention and exclusion of patients and healthy controls from baseline through completion of the follow-up assessment. For a detailed description of the demographic characteristics of patients and controls, see Table 1.

\section{Table 1 here}

After complete written and oral description of the follow-up study, written informed consent was obtained from all subjects and from a parent, if the subject was younger than 18 years of age. The follow-up study was approved by the local Ethical Committees and carried out in accordance with the Helsinki declaration. The follow-up assessment was carried out on average $5.5(\mathrm{SD}=0.4)$ years after the baseline study. Patients and controls received a small financial incentive for their participation.

\section{Assessment of psychopathology}


ICD-10 [86] diagnoses at baseline and follow-up were reached by consensus using the Schedules for Clinical Assessment in Neuropsychiatry Version 2.1 (SCAN 2.1) [87] based on video-monitored interviews and all available clinical information. Psychotic symptoms were assessed using the Scale for the Assessment of Positive Symptoms (SAPS) [4] and the Scale for the Assessment of Negative Symptoms (SANS) [3]. As shown in Table 1, psychotic symptoms were categorized into the psychoticism, disorganization, and negative symptom dimensions [5]. The age of onset of fully developed psychotic symptoms was assessed at baseline based on information derived from different sources inclusive the Interview for the Retrospective Assessment of the Onset of Schizophrenia (IRAOS) [30;52] administered to patients and parents at baseline. Based on information from IRAOS, the duration of untreated psychosis (DUP) [48] was calculated as the time interval between the onset of psychotic symptoms and the initiation of treatment, as indicated by the first appointment to the psychiatric department for psychotic symptoms. Similar to the baseline assessment, control subjects were interviewed using SCAN 2.1 again at follow-up to rule out the onset of a psychiatric disorder during the follow-up period.

\section{Assessment of socioeconomic status}

Parental education and occupation at baseline were rated into 6 social classes according to previously described criteria [31] and categorized into 3 groups (see Table 1). The parental household income at baseline was rated into one of three economic status groups (Low, Middle, or High).

\section{Cognitive assessment}

The cognitive deficits at baseline were assessed with a comprehensive neuropsychological test battery that included measures of different aspects of EF (Intra-Extra Dimensional Set Shift (IED) 
[21;25], Stocking of Cambridge (SOC) [65], Wisconsin Card Sorting Test [55] (perseverative errors according to Nelson's criteria [50]), Verbal Fluency tasks (category and letter) [50], Non-verbal Fluency Five-Point Test [68], and Trail Making Test A and B [50]. In addition, verbal memory was assessed with Buschke's Selective Reminding Task [13], attention with Rapid Visual Information Processing (RVP) (version with one target sequence of three stimuli) [18], reaction time and movement latencies with Reaction Time (RTI) [75;76], spatial short-term memory with Spatial Span (SSP) [65], and spatial working memory with Spatial Working Memory (SWM) [65]. The same version of all the neurocognitive tasks was used at the baseline and follow-up assessments. In order to reduce the number of statistical comparisons and avoid redundancy, selected core test outcome measures were combined into composite cognitive domains according to their putative content, combining test scores reflecting the same functional domain [47]. The construction of the cognitive domains was based upon a model of the executive functions as separable and different functions and on the cognitive domains reported in the literature on cognitive deficits in EOS and adult onset schizophrenia (AOS) patients, e.g. [60]. We created six composite domains: Reaction time, Motor speed, Speed of processing of EF, Set shifting, Planning, and Working memory. In addition, an Attention and a Verbal memory domain were created, each comprising a single test outcome measure. The cognitive domains and their test components are presented in detail in Figure 2.

Except one alteration, the neuropsychological tests were administered in the same fixed order at follow-up as at the baseline assessment. Based on JRJ's clinical assessment and the self-report of participants regarding recent use of alcohol and psychoactive substances on selected SCAN 2.1 items [87] at the beginning of every test session, no patient or control subject was considered intoxicated during the neuropsychological follow-up assessments. At baseline, the neuropsychological test battery was administered by BF whereas at follow-up it was administered 
by JRJ, who was blind with regard to the neuropsychological test scores at baseline. Patients and controls with incomplete cognitive data at baseline or follow-up were included in the statistical analyses and thus, the sample size varies. Apart from the SSP and SWM tests that were included in the battery somewhat late in the baseline assessment process, 12 of the EOS patients that participated at follow-up (71\%) had completed all tests at baseline, 3 patients missed one test score, and 2 patients missed two or more test scores. At follow-up, 15 EOS patients ( $88 \%$ ) had complete datasets, while 1 missed one test score, and 1 missed all computerized test scores due to computer problems. There were no missing data among controls.

\section{Data analyses}

\section{Domain scores}

When appropriate, baseline and their equivalent follow-up test raw scores (i.e. not age normed) were logarithmically transformed to approximate a normal distribution. To accurately assess the stability of cognitive functioning over time, baseline and follow-up raw scores (and the log transformed raw scores) were transformed to z-scores using the means and standard deviations (SD) of the healthy control group at baseline as the reference group [10;16]. The z-score transformation ensured that higher scores indicated better performance for all tests. Composite domain z-scores were calculated as the mean of the z-scores for the tests included in each domain (except Verbal memory and Attention domain each consisting of only one test z-score). The standard deviation of composite scores will not necessarily be 1.00 after this transformation, and consequently baseline and follow-up composite domain z-scores were restandardized using the baseline composite domain Z-score mean and SD of the control group to ensure that the control group had a restandardized baseline mean of 0.00 and a SD of 1.00. The within-subject change in performance in each cognitive domain over time was calculated by subtracting the restandardized baseline domain z- 
score from the corresponding restandardized domain z-score at follow-up to represent the development in cognitive functioning.

If a subject missed only one of the test scores included in a domain, the domain mean was calculated from the remaining tests scores and was included in the analyses. If a subject missed more than one of the test scores included in a particular domain, the domain score was considered as missing.

\section{Statistical analyses}

Chi Square tests were used for comparisons of nominal data between independent groups. All cognitive data approximated a normal distribution and analysis was conducted in three steps: First, for each cognitive domain an overall repeated measures analysis of variance (ANOVA) was conducted with group (EOS, EOP or healthy controls) as between-subjects factor and time (baseline or follow-up) as within-subjects factor. Second, unadjusted and adjusted mean changes in the EOS group and the healthy control group were compared using independent samples t-tests and analysis of covariance (ANCOVA) with the baseline cognitive domain score as covariate. Third, unadjusted and adjusted mean changes in the EOS and EOP groups were compared using independent samples t-tests and ANCOVA with the baseline domain score, DUP score, and ratings of severity of negative and disorganization symptoms as covariates. The comparisons of the EOS group with the healthy controls and with the EOP group were conducted separately because different covariates were included. The baseline domain z-score was chosen as covariate, because preliminary analyses revealed significant and inverse correlations between baseline domain z-scores and change in the equivalent domain z-scores. Psychoticism symptom dimension severity was not included as a covariate because previous findings of no or minimal relationships to cognitive deficits in AOS [33;59]. Parental education/occupation and household income at baseline did not significantly 
predict change in any cognitive domain z-score and were consequently not included as covariates in the statistical models. To avoid violation of the ANCOVA assumption of homogeneity of regressions slopes, two outlying results in the Speed of processing of EF domain were excluded from the analyses (outliers were defined as change scores $>2$ SD above or $<-2$ SD below the mean in the EOS and control group, respectively). Independent samples t-tests were used to compare the baseline and follow-up cognitive domain mean z-scores between the EOS and healthy control groups and between the EOS and EOP groups. Mann-Whitney tests were used to compare psychopathological data between the groups, while Wilcoxon tests were used to compare these data within the groups. Due to the small sample sizes and related increased risk for Type II errors, we did not correct for multiple comparisons to enable detection of relatively small effects (alpha was set at $\mathrm{p}<.05)$.

Spearman's rho was calculated in order to evaluate possible cross-sectional associations between symptom dimension severity ratings and cognitive domain scores at baseline and follow-up in the EOS group. Spearman's rho was also calculated to assess possible associations between change in the cognitive domain score and the change in symptom dimension severity ratings (i.e. the symptom dimension rating at follow-up minus the corresponding rating at baseline) during the follow-up interval in this clinical group. Pearson correlation was calculated to assess possible associations between the changes in cognitive domain z-scores in EOS patients. Analyses were conducted using SPSS 11.0.

\section{Supplementary analyses}

Regarding co-morbid ICD-10 psychoactive substance abuse disorder (SUD), the adjusted comparisons of mean change in each cognitive domain score between EOS and controls were reanalysed after exclusion of EOS patients with co-morbid SUD at baseline or follow-up. Similarly, 
the adjusted comparisons of mean change in each cognitive domain score between the EOS and EOP patient groups were reanalysed after exclusion of EOS and EOP patients with co-morbid SUD at baseline or follow-up. Results from these reanalyses are only reported in the Results section if they differed from the results obtained in the corresponding comparisons including the complete samples.

\section{Results}

Psychopathology and sociodemographics

The baseline diagnosis of schizophrenia in the EOS group was confirmed in all cases at follow-up. In contrast, $91 \%$ of baseline diagnoses in the EOP group were changed at the follow-up assessment, indicating a high prevalence of diagnostic instability in this group. Appendix A presents the follow-up diagnostic distributions of these subgroups. The absence of psychiatric diseases in the healthy controls was confirmed at follow-up.

The current follow-up EOS patient group appears to be representative of the complete baseline EOS group, as no statically significant differences were found in baseline psychopathology, education, demographics, or cognition between the follow-up EOS patient group and the EOS patients not participating in the follow-up assessment. As shown in Table 1, the psychoticism and negative symptom dimension severity ratings improved significantly from baseline to follow-up in the EOS group, whereas no significant difference was observed regarding disorganisation symptom dimension severity ratings.

\section{Cognitive performance}

The repeated measures ANOVA indicated no significant interactions between group and time in any cognitive domain (see Figure 2). Thus, in this unadjusted perspective, one cannot reject the 
possibility of a comparable change in each specific cognitive function in the three groups. A significant main effect of group was observed in all eight cognitive domains, and both patient groups generally performed worse than the healthy controls group. Finally, a significant main effect of time was found in all cognitive domains, except the Reaction time domain. Scores for all significant domains increased from baseline to follow-up, except the Verbal memory domain, which deteriorated significantly.

Figure 2 here

\section{EOS patients versus healthy controls}

All baseline and follow-up mean cognitive domain z-scores were significantly lower in the EOS group than in the control group, except for the follow-up mean Reaction Time domain z-score (see Figure 2) (the p-values are not shown). The unadjusted comparisons of mean change over time did not show statistically significant differences between the two groups, but the confidence intervals of the unadjusted mean change in the Attention, Speed of processing of EF, and Set shifting domains indicate significant increase in the healthy controls, but not in the EOS group (see Table 2). Remarkably, a significant deterioration of the Verbal memory domain was found in the healthy controls.

When comparisons of change scores were adjusted for baseline performance, analyses revealed a significant difference in the mean change in Attention and Set shifting domain z-score over time between EOS and controls (see Table 2). As shown in Table 2, the confidence intervals of the adjusted mean change in the Attention and Set shifting domains indicate significant change in the healthy controls, but not in the EOS group.

Table 2 here 
After exclusion of EOS patients with co-morbid ICD-10 SUD at any time point, reanalyses revealed a non-significant adjusted difference in mean change in the Attention domain z-score between the remaining EOS patients and the healthy controls $\left(\mathrm{F}_{(1,46)}=3.43, \mathrm{p}=.071\right)$.

\section{EOS versus EOP patients}

Neither adjusted nor unadjusted comparisons revealed significant differences in mean change in any cognitive domain between the EOS and EOP groups (data not shown). None of the cross-sectional differences in any cognitive domain at baseline or follow-up between the EOS and EOP groups attained statistical significance (see Figure 2).

\section{Correlations between cognitive performance and psychopathology ratings in EOS patients} At baseline, two significant and large cross-sectional correlations were observed between the Working memory $\mathrm{z}$-score and psychoticism symptom dimension severity $(\mathrm{N}=9)($ rho $=.70, \mathrm{p}=$ $.035)$ and the negative symptom dimension severity $(\mathrm{N}=9)($ rho $=-.70, \mathrm{p}=.036)$ in the EOS group. No other significant correlations were observed between any clinical symptom dimension ratings and cognitive domain z-scores at baseline.

At follow-up, significant cross-sectional correlations were observed between the negative symptom dimension severity and Verbal memory (rho $=-.49, \mathrm{p}=.047)$, Attention (rho = -.56, $\mathrm{p}=.032$ ), Speed of processing of EF (rho $=-.71, \mathrm{p}=.002)$, and Working Memory z-score (rho $=-.58, \mathrm{p}=.018)$. In addition, large significant cross-sectional correlations were found between the disorganization symptom dimension severity and Set Shifting (rho $=-.54, \mathrm{p}=.024)$ and Speed of processing of EF $\mathrm{z}$-score (rho $=-.66, \mathrm{p}=.004)$ at follow-up. No other significant correlations were observed between any clinical symptom ratings and cognitive domain z-scores at follow-up. 
Analyses of associations between the changes in cognitive domain z-scores in EOS patients revealed only two significant correlations, namely between change in Attention and change in Reaction time $\mathrm{z}$-score $(\mathrm{r}=.59, \mathrm{p}=.033)$ and between the latter and change Working memory $\mathrm{z}$ score $(\mathrm{r}=.82, \mathrm{p}=.007)$.

Analyses of associations between the changes in cognitive domain z-scores and the changes in symptom dimension severity ratings during the follow-up interval revealed large negative correlations between the change in Speed of processing of EF Z-score and change in negative (rho = $-.68, \mathrm{p}=.004)$, psychoticism $(\mathrm{rho}=-.67, \mathrm{p}=.004)$, and disorganization symptom dimension severity (rho $=-.71, \mathrm{p}=.002)$. Thus, reduced psychotic symptom severity was associated with improved Speed of processing of EF. None of the remaining correlations obtained statistical significance.

\section{Discussion}

At baseline, all eight specific cognitive domains were significantly impaired in EOS patients. In terms of the Reaction time, Motor speed, Speed of processing of EF, Planning, Working memory, and the Verbal memory domain, no significant difference in change in performance was observed between EOS patients and controls during the five-year follow-up interval. These results may suggest normal development in these specific cognitive functions that include components of attention and EF. Thus, it is possible that these specific cognitive deficits may be stable, trait-like aspects of EOS throughout this early illness phase. The adjusted comparison of change in attention and set shifting revealed a significantly larger increase in healthy controls than in EOS patients which was not observed in analyses unadjusted for baseline scores. The deficits in attention and set shifting at baseline resulted in substantial adjustment of the change score, but we suggest the results may reflect subnormal development in attention and set shifting in EOS patients during the first 5 
years after full clinical presentation. After exclusion of patients with co-morbid ICD-10 SUD at baseline and follow-up, the adjusted between-group difference in attention change score lost statistical significance. However, the exclusion of a relatively large proportion of EOS patients decreased statistical power and the lack of significance may reflect a Type II error.

The non-significant increase in Reaction time, Planning, and Working memory domains in the healthy controls suggest that these components of attention and EF may have approximated their mature functional level before or around the age at the baseline assessment. In contrast, the significant improvement with age in Attention, Set shifting, and Speed of processing of EF domains in the healthy controls may reflect functional progression throughout late adolescence and possibly in early adulthood. Developments in aspects of EF through these ages has previously been demonstrated in healthy subjects $[19 ; 37 ; 73]$. The improvement in set shifting observed in our controls is in accordance with previous findings $[37 ; 51 ; 73 ; 74]$ but earlier maturation has also been reported $[17 ; 19 ; 83]$. The significant improvement in attention observed in the healthy controls is also in accordance with earlier findings $[2 ; 24 ; 53 ; 79]$.

We interpret the observed pattern of results as suggesting significant subnormal development in two of the three aspects of attention and EF with protracted maturational trajectories that overlap the age of onset of EOS. However, no significant developmental difference in the specific cognitive functions was found between EOS and EOP patients. Thus, the subnormal development in attention and set shifting may not be specific to EOS but could represent cognitive developmental deficits associated with psychotic disorders in general. The relative worsening of the set shifting and attention deficits in the EOS patients may reflect disruptive interactions among the EOS disease processes, or factors associated with the illness, and the neural networks mediating these functions. 
However, they may also reflect the development of non-specific cognitive risk factors with protracted maturational trajectories.

No differential deterioration was observed in the EOS patients through this illness phase, although possible deterioration of attention and set shifting cannot be ruled out. Thus, no clear cognitive indications of neurodegenerative processes in EOS patients were detected, and the observed subnormal maturational gains in components of attention and EF are in accordance with the neurodevelopmental model [58;82].

Two previous studies examining the development of EF in EOS patients using WCST found stability, and lack of improvement, respectively, [16;64]. In terms of attention development in EOS patients, previous studies have observed either an abnormal lack of improvement [64] or deterioration in aspects of attention through late adolescence and early adulthood [24;62]. However, stability in attention deficits has also been reported over a relatively short follow-up period in EOS patients [16]. It is possible that the time frame for the longitudinal study by Cervellione and colleagues (2007) [16] may have been too short to detect possible developmental differences. Thus, the observed subnormal developments of attention and set shifting are in line with the EOS studies with longer follow-up intervals.

Previous findings on the development of set shifting deficits in AOS patients are conflicting. Thus, longitudinal studies suggest stability [1;34], while other (cross-sectional) studies suggest deterioration $[38 ; 66 ; 67]$. Longitudinal studies suggest stability in attention in first-episode AOS patients $[15 ; 28]$. These longitudinal results from AOS studies are in line with the hypothesis of particular developmental effects of the schizophrenia disease processes on cognitive components that have not completed their developmental trajectories around the time of illness onset. But they 
are also in line with the hypothesis, that the attention and set shifting functions may represent cognitive risk factors.

The observed lack of differential development between EOS and controls in planning and motor functioning are consistent with previous findings [24;64], although somewhat different aspects of motor function were assessed presently. The lack of significant differential development in verbal memory between EOS patients and healthy controls contrasts with previous findings [24]. However, we observed unexpected and significant deterioration of verbal memory in the healthy controls, and it is possible that tester-effects may explain this finding.

Only few significant associations were found between cognition at baseline and follow-up and psychopathology at the same time point. We interpret these results as suggesting a large degree of independence between psychopathology and cognitive deficits in EOS both at illness onset and chronic phase. This is consistent with most previous studies [7;11;24;46;81], although not all [53]. The significant association between worse psychoticism dimension symptom severity and better working memory performance at baseline is in accordance with earlier findings of associations between more psychotic symptoms and better immediate visual recall [61] and more correct WCST responses [8] in AOS patients. However, this current association may be spurious and may reflect a Type I error. In terms of cognitive change, only the change in Speed of processing of EF was significantly associated with change in symptom severity in the EOS patients, which is in line previous studies of both EOS [16] and AOS patients [56]. In conclusion, we consider both the specific cognitive deficits and their development in our EOS sample to be essentially unaffected by the psychopathological symptoms. 
The many insignificant correlations observed between the changes in the different cognitive domains over time may reflect low reliability of change scores, but may also indicate that the cognitive domains develop independently in EOS patients. In particular, no significant association was found between the changes in attention and set shifting, which may indicate independence between the developments of the two specific cognitive functions with subnormal maturational development in EOS patients.

Due to the naturalistic design of the current study, possible confounding effects of antipsychotic medications on the specific cognitive functions could not be controlled. However, the enhancing influence of antipsychotic medications on cognitive functions may be minor, as the improvement in cognitive function associated with atypical $[43 ; 88]$ and typical antipsychotic treatment is relatively small [56]. Although not conclusive, no statistically significant differences in cognitive deficits have been found between EOS patients treated with antipsychotic medications from those untreated $[81 ; 85]$. Thus, the observed subnormal development in attention and set shifting in EOS patients is unlikely to be related to antipsychotic medication effects.

\section{Methodological considerations}

We recognize that our patient sample sizes are small which increases the risk of Type II errors. In particular, the result of the adjusted comparison of change in the Speed of processing of EF performance between EOS patients and controls appears ambiguous (cf. Table 2). Due to the relatively low number of participants, factor analysis was not used to derive cognitive domains. The development in specific cognitive functions may be associated with baseline FSIQ and possible change in FSIQ during the follow-up interval. However, it was not possible to adjust the betweengroup comparisons of change in specific cognitive functions for FSIQ. Given the diagnostic heterogeneity of the EOP group at follow-up, in particular, the onset of schizophrenia in some of the 
patients, the interpretation of the comparisons of the development in specific cognitive functions in the EOS and EOP groups remains ambiguous.

A very high diagnostic stability of EOS was found in the current study, but the follow-up diagnostic evaluation was not blind to the baseline diagnosis. Our finding is in accordance with the high degree of diagnostic stability of EOS observed in studies with diagnostic reassessments blind to initial diagnosis $[32 ; 35]$ and without (or probably without) blind reassessment $[40 ; 69 ; 54 ; 72]$ although lower estimates of diagnostic stability of EOS also have been reported [80]. The diagnostic stability of Other non-organic psychotic disorders (F28) in our EOP subgroup was very low. This estimate is in accordance with the relatively low estimates of stability for early-onset atypical psychosis [35] and early-onset psychosis not otherwise specified [23;40].

We conclude that significant deficits were present in all specific cognitive domains at the time of the first episode in EOS patients. The post-psychotic development of most specific cognitive functions may be characterized as normal, indicating relatively stable cognitive deficits during this early illness phase. However, significant developmental delays in components of attention and $\mathrm{EF}$ were observed in EOS patients from the time of full clinical presentation to the chronic phase five years later, while results concerning the development of speed of processing of EF were ambiguous. The development of all specific cognitive functions, except the speed of processing of EF, was independent of the course of psychopathological symptom dimensions. The subnormal cognitive development in EOS patients was confined to the specific cognitive functions that were developmentally immature at the time of full clinical presentation. Further characterization of the developmental trajectories of the specific cognitive functions as well as their possible associations to functional outcome in EOS patients may eventually lead to invention of treatment strategies to 
alleviate the subnormal development of immature specific cognitive functions and improve the relatively stable specific cognitive deficits in this early illness phase of EOS.

\section{Appendix A}

Baseline and follow-up diagnoses of the individual EOS and EOP patients

\begin{tabular}{|c|c|c|}
\hline Case & Baseline diagnosis & Follow-up diagnosis \\
\hline \multicolumn{3}{|c|}{ EOS patients } \\
\hline 1 & Paranoid schizophrenia (F20.0) & $\begin{array}{l}\text { Residual schizophrenia } \\
\text { (F20.50) }\end{array}$ \\
\hline 2 & Paranoid schizophrenia (F20.0) & $\begin{array}{l}\text { Paranoid schizophrenia } \\
\text { (F20.00) }\end{array}$ \\
\hline 3 & Paranoid schizophrenia (F20.0) & $\begin{array}{l}\text { Paranoid schizophrenia } \\
\text { (F20.00) }\end{array}$ \\
\hline 4 & Paranoid schizophrenia (F20.0) & $\begin{array}{l}\text { Paranoid schizophrenia } \\
\text { (F20.04) }\end{array}$ \\
\hline 5 & Paranoid schizophrenia (F20.0) & $\begin{array}{l}\text { Paranoid schizophrenia } \\
\text { (F20.04) }\end{array}$ \\
\hline 6 & Paranoid schizophrenia (F20.0) & $\begin{array}{l}\text { Residual Schizophrenia } \\
\text { (F20.50) }\end{array}$ \\
\hline 7 & Paranoid schizophrenia (F20.0) & $\begin{array}{l}\text { Paranoid schizophrenia } \\
\text { (F20.00) }\end{array}$ \\
\hline 8 & Paranoid schizophrenia (F20.0) & $\begin{array}{l}\text { Paranoid schizophrenia } \\
\text { (F20.05) }\end{array}$ \\
\hline 9 & Paranoid schizophrenia (F20.0) & $\begin{array}{l}\text { Paranoid schizophrenia } \\
\text { (F20.04) }\end{array}$ \\
\hline 10 & Paranoid schizophrenia (F20.0) & $\begin{array}{l}\text { Paranoid schizophrenia } \\
\text { (F20.04) }\end{array}$ \\
\hline 11 & Paranoid schizophrenia (F20.0) & $\begin{array}{l}\text { Paranoid schizophrenia } \\
\text { (F20.04) }\end{array}$ \\
\hline 12 & Paranoid schizophrenia (F20.0) & $\begin{array}{l}\text { Paranoid schizophrenia } \\
\text { (F20.00) }\end{array}$ \\
\hline 13 & $\begin{array}{l}\text { Hebephrenic schizophrenia } \\
\text { (F20.1) }\end{array}$ & $\begin{array}{l}\text { Hebephrenic } \\
\text { schizophrenia (F20.10) }\end{array}$ \\
\hline 14 & $\begin{array}{l}\text { Hebephrenic schizophrenia } \\
\text { (F20.1) }\end{array}$ & $\begin{array}{l}\text { Hebephrenic } \\
\text { schizophrenia (F20.10) }\end{array}$ \\
\hline 15 & $\begin{array}{l}\text { Undifferentiated schizophrenia } \\
\text { (F20.3) }\end{array}$ & $\begin{array}{l}\text { Undifferentiated } \\
\text { schizophrenia (F20.34) }\end{array}$ \\
\hline 16 & $\begin{array}{l}\text { Undifferentiated schizophrenia } \\
\text { (F20.3) }\end{array}$ & $\begin{array}{l}\text { Undifferentiated } \\
\text { schizophrenia (F20.34) }\end{array}$ \\
\hline 17 & $\begin{array}{l}\text { Schizophrenia, unspecified } \\
\text { (F20.9) }\end{array}$ & $\begin{array}{l}\text { Schizophrenia, } \\
\text { unspecified (F20.95) }\end{array}$ \\
\hline \multicolumn{3}{|c|}{ EOP patients } \\
\hline 1 & Delusional disorder (F22.0) & $\begin{array}{l}\text { No psychiatric disorder } \\
(\mathrm{Z} 04)^{1}\end{array}$ \\
\hline 2 & $\begin{array}{l}\text { Other acute predominantly } \\
\text { delusional psychotic disorders }\end{array}$ & $\begin{array}{l}\text { Disturbance of activity } \\
\text { and attention (F90.0) }\end{array}$ \\
\hline
\end{tabular}




\begin{tabular}{|c|c|c|}
\hline & (F23.3) & \\
\hline 3 & $\begin{array}{l}\text { Acute and transient psychotic } \\
\text { disorder, unspecified (F23.9) }\end{array}$ & $\begin{array}{l}\text { Moderate depressive } \\
\text { episode (F32.1) }\end{array}$ \\
\hline 4 & $\begin{array}{l}\text { Other nonorganic psychotic } \\
\text { disorders (F28) }\end{array}$ & $\begin{array}{l}\text { No psychiatric disorder } \\
(\mathrm{Z} 04)^{1}\end{array}$ \\
\hline 5 & $\begin{array}{l}\text { Other nonorganic psychotic } \\
\text { disorders (F28) }\end{array}$ & $\begin{array}{l}\text { Paranoid schizophrenia } \\
\text { (F20.04) }\end{array}$ \\
\hline 6 & $\begin{array}{l}\text { Other nonorganic psychotic } \\
\text { disorders (F28) }\end{array}$ & $\begin{array}{l}\text { Paranoid schizophrenia } \\
\text { (F20.00) }\end{array}$ \\
\hline 7 & $\begin{array}{l}\text { Other nonorganic psychotic } \\
\text { disorders (F28) }\end{array}$ & $\begin{array}{l}\text { Paranoid schizophrenia } \\
\text { (F20.05) }\end{array}$ \\
\hline 8 & $\begin{array}{l}\text { Other nonorganic psychotic } \\
\text { disorders (F28) }\end{array}$ & $\begin{array}{l}\text { Recurrent depressive } \\
\text { disorder }^{2}(\mathrm{~F} 33.1)\end{array}$ \\
\hline 9 & $\begin{array}{l}\text { Other nonorganic psychotic } \\
\text { disorders (F28) }\end{array}$ & Panic disorder (F41.0) \\
\hline 10 & $\begin{array}{l}\text { Other nonorganic psychotic } \\
\text { disorders (F28) }\end{array}$ & $\begin{array}{l}\text { Other nonorganic psychotic } \\
\text { disorders (F28) }\end{array}$ \\
\hline 11 & $\begin{array}{l}\text { Other nonorganic psychotic } \\
\text { disorders (F28) }\end{array}$ & $\begin{array}{l}\text { Delusional disorder } \\
(\mathrm{F} 22.0)\end{array}$ \\
\hline
\end{tabular}

${ }^{1}$ Examination and observation for other reasons

2 current episode moderate

In terms of follow-up diagnoses in the EOS patient group, a positive predictive value of $100 \%$ was observed, when including 2 EOS patients (12\%), who had complete remission at follow-up without antipsychotic treatment at that time point. Forty seven $\%$ had a continuous course and $41 \%$ incomplete remission. In terms of the EOP patient group, the diagnostic stability of Other nonorganic psychotic disorders (F28) was very low (positive predictive value of $13 \%$ ).

\section{Funding}

This work was supported by H:S The Foundation of Copenhagen Hospital Services [grant number 2/03r/BBH]; Danish Research Agency, Ministry for Science, Technology, and Innovation [grant number 22-03-0365]; Danish Agency for Science, Technology, and Innovation [grant number 27106-0453]; The Danielsen Foundation [105690]; The Hermansen Foundation [grant number 009620001].

\section{References}


1. Albus M, Hubmann W, Scherer J, Dreikorn B, Hecht S, Sobizack N, Mohr F (2002) A prospective 2year follow-up study of neurocognitive functioning in patients with first-episode schizophrenia. Eur Arch Psychiatry Clin Neurosci 252:262-267

2. Anderson VA, Anderson P, Northam E, Jacobs R, Catroppa C (2001) Development of executive functions through late childhood and adolescence in an Australian sample. Dev Neuropsychol 20:385-406

3. Andreasen NC (1984) Scale for the Assessment of Negative Symptoms (SANS). The University of Iowa, Iowa City.

4. Andreasen NC (1984) Scale for the Assessment of Positive Symptoms (SAPS). 1984. The University of Iowa, Iowa City

5. Andreasen NC, Arndt S, Alliger R, Miller D, Flaum M (1995) Symptoms of schizophrenia. Methods, meanings, and mechanisms. Arch Gen Psychiatry 52:341-351

6. Asarnow RF, Asamen J, Granholm E, Sherman T, Watkins JM, Williams ME (1994) Cognitive/neuropsychological studies of children with a schizophrenic disorder. Schizophr Bull 20:647-669

7. Banaschewski T, Schulz E, Martin M, Remschmidt H (2000) Cognitive functions and psychopathological symptoms in early-onset schizophrenia. Eur Child Adolesc Psychiatry 9:11-20

8. Basso MR, Nasrallah HA, Olson SC, Bornstein RA (1998) Neuropsychological correlates of negative, disorganized and psychotic symptoms in schizophrenia. Schizophr Res 31:99-111

9. Bedwell JS, Keller B, Smith AK, Hamburger S, Kumra S, Rapoport JL (1999) Why does postpsychotic IQ decline in childhood-onset schizophrenia? Am J Psychiatry 156:1996-1997 
10. Bilder RM, Goldman RS, Robinson D, Reiter G, Bell L, Bates JA, Pappadopulos E, Willson DF, Alvir JM, Woerner MG, Geisler S, Kane JM, Lieberman JA (2000) Neuropsychology of first-episode schizophrenia: initial characterization and clinical correlates. Am J Psychiatry 157:549-559

11. Brickman AM, Buchsbaum MS, Bloom R, Bokhoven P, Paul-Odouard R, Haznedar MM, Dahlman KL, Hazlett EA, Aronowitz J, Heath D, Shihabuddin L (2004) Neuropsychological functioning in first-break, nevermedicated adolescents with psychosis. J Nerv Ment Dis 192:615-622

12. Burd L, Kerbeshian J (1987) A North Dakota prevalence study of schizophrenia presenting in childhood. J Am Acad Child Adolesc Psychiatry 26:347-350

13. Buschke H, Fuld PA (1974) Evaluating storage, retention, and retrieval in disordered memory and learning. Neurology 24:1019-1025

14. Cannon M, Jones P, Huttunen MO, Tanskanen A, Huttunen T, Rabe-Hesketh S, Murray RM (1999) School performance in Finnish children and later development of schizophrenia: a population-based longitudinal study. Arch Gen Psychiatry 56:457-463

15. Censits DM, Ragland JD, Gur RC, Gur RE (1997) Neuropsychological evidence supporting a neurodevelopmental model of schizophrenia: a longitudinal study. Schizophr Res 24:289-298

16. Cervellione KL, Burdick KE, Cottone JG, Rhinewine JP, Kumra S (2007) Neurocognitive deficits in adolescents with schizophrenia: longitudinal stability and predictive utility for short-term functional outcome. J Am Acad Child Adolesc Psychiatry 46:867-878

17. Chelune GJ, Baer RA (1986) Developmental Norms for the Wisconsin Card Sorting test. J Clin and Exp Neuropsychol 8:219-228 
18. Coull JT, Frith CD, Frackowiak RS, Grasby PM (1996) A fronto-parietal network for rapid visual information processing: a PET study of sustained attention and working memory. Neuropsychologia 34:1085-1095

19. De Luca CR, Wood SJ, Anderson V, Buchanan JA, Proffitt TM, Mahony K, Pantelis C (2003) Normative data from the CANTAB. I: development of executive function over the lifespan. J Clin Exp Neuropsychol $25: 242-254$

20. Denckla MB (1996) A theory and model of executive function: A neuropsychological perspective. In: Lyon GR, Krasnegor NA (eds) Attention, memory, and executive function. Poul H. Brookes, Baltimore, pp 263-277

21. Downes JJ, Roberts AC, Sahakian BJ, Evenden JL, Morris RG, Robbins TW (1989) Impaired extradimensional shift performance in medicated and unmedicated Parkinson's disease: evidence for a specific attentional dysfunction. Neuropsychologia 27:1329-1343

22. Fagerlund B, Pagsberg AK, Hemmingsen RP (2006) Cognitive deficits and levels of IQ in adolescent onset schizophrenia and other psychotic disorders. Schizophr Res 85:30-39

23. Fraguas D, de Castro MJ, Medina O, Parellada M, Moreno D, Graell M, Merchan-Naranjo J, Arango C (2008) Does diagnostic classification of early-onset psychosis change over follow-up? Child Psychiatry Hum Dev 39:137-145

24. Frangou S, Hadjulis M, Vourdas A (2008) The Maudsley early onset schizophrenia study: cognitive function over a 4-year follow-up period. Schizophr Bull 34:52-59

25. Fray PJ, Robbins TW, Sahakian BJ (1996) Neuropsychiatric applications of CANTAB. Int Geriatric Psychiatry 11:329-336

26. Fuster JM (1999) Synopsis of function and dysfunction of the frontal lobe. Acta Psychiatr Scand Suppl $395: 51-57$ 
27. Gochman PA, Greenstein D, Sporn A, Gogtay N, Keller B, Shaw P, Rapoport JL (2005) IQ stabilization in childhood-onset schizophrenia. Schizophr Res 77:271-277

28. Gold S, Arndt S, Nopoulos P, O'Leary DS, Andreasen NC (1999) Longitudinal study of cognitive function in first-episode and recent-onset schizophrenia. Am J Psychiatry 156:1342-1348

29. Groom MJ, Jackson GM, Calton TG, Andrews HK, Bates AT, Liddle PF, Hollis C (2008) Cognitive deficits in early-onset schizophrenia spectrum patients and their non-psychotic siblings: a comparison with ADHD. Schizophr Res 99:85-95

30. Hafner H, Riecher-Rossler A, Hambrecht M, Maurer K, Meissner S, Schmidtke A, Fatkenheuer B, Loffler W, van der HW (1992) IRAOS: an instrument for the assessment of onset and early course of schizophrenia. Schizophr Res 6:209-223

31. Hansen, E. J. (1986) Danskernes levekår - 1986 sammenholdt med 1976. En interviewundersøgelse af 4.500 voksne danskere. Hans Reitzels Forlag A/S, Copenhagen

32. Helgeland MI, Torgersen S (2005) Stability and prediction of schizophrenia from adolescence to adulthood. Eur Child Adolesc Psychiatry 14:83-94

33. Heydebrand G, Weiser M, Rabinowitz J, Hoff AL, DeLisi LE, Csernansky JG (2004) Correlates of cognitive deficits in first episode schizophrenia. Schizophr Res 68:1-9

34. Hoff AL, Svetina C, Shields G, Stewart J, DeLisi LE (2005) Ten year longitudinal study of neuropsychological functioning subsequent to a first episode of schizophrenia. Schizophr Res 78:27-34

35. Hollis C (2000) Adult outcomes of child- and adolescent-onset schizophrenia: diagnostic stability and predictive validity. Am J Psychiatry 157:1652-1659 
36. Holmen A, Juuhl-Langseth M, Thormodsen R, Melle I, Rund BR (2009) Neuropsychological Profile in Early-Onset Schizophrenia-Spectrum Disorders: Measured With the MATRICS Battery. Schizophr Bull doi:10.1093/schbul/sbn174

37. Huizinga M, Dolan CV, van der Molen MW (2006) Age-related change in executive function: developmental trends and a latent variable analysis. Neuropsychologia 44:2017-2036

38. Hutton SB, Puri BK, Duncan LJ, Robbins TW, Barnes TR, Joyce EM (1998) Executive function in firstepisode schizophrenia. Psychol Med 28:463-473

39. Jacobsen LK, Rapoport JL (1998) Research update: childhood-onset schizophrenia: implications of clinical and neurobiological research. J Child Psychol Psychiatry 39:101-113

40. Jarbin H, von Knorring AL (2003) Diagnostic stability in adolescent onset psychotic disorders. Eur Child Adolesc Psychiatry 12:15-22

41. Jepsen JR, Fagerlund B, Pagsberg AK, Christensen AM, Hilker RW, Nordentoft M, Mortensen EL (2009) Course of intelligence deficits in early onset, first episode schizophrenia: a controlled, 5-year longitudinal study. Eur Child Adolesc Psychiatry doi: 10.1007/s00787-009-0053-4

42. Jurado MB, Rosselli M (2007) The elusive nature of executive functions: a review of our current understanding. Neuropsychol Rev 17:213-233

43. Keefe RS, Bilder RM, Davis SM, Harvey PD, Palmer BW, Gold JM, Meltzer HY, Green MF, Capuano G, Stroup TS, McEvoy JP, Swartz MS, Rosenheck RA, Perkins DO, Davis CE, Hsiao JK, Lieberman JA (2007) Neurocognitive effects of antipsychotic medications in patients with chronic schizophrenia in the CATIE Trial. Arch Gen Psychiatry 64:633-647 
44. Kenny JT, Friedman L, Findling RL, Swales TP, Strauss ME, Jesberger JA, Schulz SC (1997) Cognitive impairment in adolescents with schizophrenia. Am J Psychiatry 154:1613-1615

45. Kester HM, Sevy S, Yechiam E, Burdick KE, Cervellione KL, Kumra S (2006) Decision-making impairments in adolescents with early-onset schizophrenia. Schizophr Res 85:113-123

46. Kravariti E, Morris RG, Rabe-Hesketh S, Murray RM, Frangou S (2003) The Maudsley early onset schizophrenia study: cognitive function in adolescents with recent onset schizophrenia. Schizophr Res 61:137-148

47. Kumra S, Wiggs E, Bedwell J, Smith AK, Arling E, Albus K, Hamburger SD, McKenna K, Jacobsen LK, Rapoport JL, Asarnow RF (2000) Neuropsychological deficits in pediatric patients with childhood-onset schizophrenia and psychotic disorder not otherwise specified. Schizophr Res 42:135-144

48. Larsen TK, McGlashan TH, Moe LC (1996) First-episode schizophrenia: I. Early course parameters. Schizophr Bull 22:241-256

49. Lee P, Moss S, Friedlander R, Donnelly T, Honer W (2003) Early-onset schizophrenia in children with mental retardation: diagnostic reliability and stability of clinical features. J Am Acad Child Adolesc Psychiatry 42:162169

50. Lezak MD (1995) Neuropsychological Assessment, Third Edition. Oxford University Press, Inc., Oxford

51. Lin CC, Chen WJ, Yang HJ, Hsiao CK, Tien AY (2000) Performance on the Wisconsin Card Sorting Test among adolescents in Taiwan: norms, factorial structure, and relation to schizotypy. J Clin Exp Neuropsychol 22:69-79

52. Maurer K, Hafner H (1995) Methodological aspects of onset assessment in schizophrenia. Schizophr Res 15:265-276 
53. Mayoral M, Zabala A, Robles O, Bombin I, Andres P, Parellada M, Moreno D, Graell M, Medina O, Arango C (2008) Neuropsychological functioning in adolescents with first episode psychosis: A two-year follow-up study. Eur Psychiatry 23:375-383

54. McClellan J, McCurry C (1999) Early onset psychotic disorders: diagnostic stability and clinical characteristics. Eur Child Adolesc Psychiatry 8:I/13-I/19

55. Milner B (1963) Effects of different brain lesions on card sorting. Arch Neurol 9:100-110

56. Mishara AL, Goldberg TE (2004) A meta-analysis and critical review of the effects of conventional neuroleptic treatment on cognition in schizophrenia: opening a closed book. Biol Psychiatry 55:1013-1022

57. Miyake A, Friedman NP, Emerson MJ, Witzki AH, Howerter A, Wager TD (2000) The unity and diversity of executive functions and their contributions to complex "Frontal Lobe" tasks: a latent variable analysis. Cognit Psychol 41:49-100

58. Murray RM, Lewis SW (1987) Is schizophrenia a neurodevelopmental disorder? Br Med J (Clin Res Ed) 295:681-682

59. Nieuwenstein MR, Aleman A, de Haan EH (2001) Relationship between symptom dimensions and neurocognitive functioning in schizophrenia: a meta-analysis of WCST and CPT studies. Wisconsin Card Sorting Test. Continuous Performance Test. J Psychiatr Res 35:119-125

60. Nuechterlein KH, Barch DM, Gold JM, Goldberg TE, Green MF, Heaton RK (2004) Identification of separable cognitive factors in schizophrenia. Schizophr Res 72:29-39

61. O'Leary DS, Flaum M, Kesler ML, Flashman LA, Arndt S, Andreasen NC (2000) Cognitive correlates of the negative, disorganized, and psychotic symptom dimensions of schizophrenia. J Neuropsychiatry Clin Neurosci 12:4-15 
62. Oie M, Hugdahl K (2008) A 10-13 year follow-up of changes in perception and executive attention in patients with early-onset schizophrenia: A dichotic listening study. Schizophr Res 106:29-32

63. Oie M, Rund BR (1999) Neuropsychological deficits in adolescent-onset schizophrenia compared with attention deficit hyperactivity disorder. Am J Psychiatry 156:1216-1222

64. Oie M, Sundet K, Rund BR (2008) Neurocognitive Decline in Early-Onset Schizophrenia Compared With ADHD and Normal Controls: Evidence From a 13-Year Follow-up Study. Schizophr Bull doi: $10.1093 /$ schbul/sbn127

65. Owen AM, Downes JJ, Sahakian BJ, Polkey CE, Robbins TW (1990) Planning and spatial working memory following frontal lobe lesions in man. Neuropsychologia 28:1021-1034

66. Pantelis C, Barber FZ, Barnes TR, Nelson HE, Owen AM, Robbins TW (1999) Comparison of setshifting ability in patients with chronic schizophrenia and frontal lobe damage. Schizophr Res 37:251-270

67. Pantelis C, Wood SJ, Proffitt TM, Testa R, Mahony K, Brewer W, Buchanan JA, Velakoulis D, McGorry PD (2009) Attentional set-shifting ability in first-episode and established schizophrenia: Relationship to working memory. Schizophr Res 112:104-113

68. Regard M, Strauss E, Knapp P (1982) Children’s Production on Verbal and Non-verbal Fluency Tasks. Percept Mot Skills 55:839-844

69. Remschmidt H, Martin M, Fleischhaker C, Theisen FM, Hennighausen K, Gutenbrunner C, Schulz E (2007) Forty-two-years later: the outcome of childhood-onset schizophrenia. J Neural Transm 114:505-512

70. Remschmidt HE, Schulz E, Martin M, Warnke A, Trott GE (1994) Childhood-onset schizophrenia: history of the concept and recent studies. Schizophr Bull 20:727-745 
71. Rhinewine JP, Lencz T, Thaden EP, Cervellione KL, Burdick KE, Henderson I, Bhaskar S, Keehlisen L, Kane J, Kohn N, Fisch GS, Bilder RM, Kumra S (2005) Neurocognitive profile in adolescents with early-onset schizophrenia: clinical correlates. Biol Psychiatry 58:705-712

72. Ropcke B, Eggers C (2005) Early-onset schizophrenia: a 15-year follow-up. Eur Child Adolesc Psychiatry 14:341-350

73. Rosso IM, Young AD, Femia LA, Yurgelun-Todd DA (2004) Cognitive and emotional components of frontal lobe functioning in childhood and adolescence. Ann N Y Acad Sci 1021:355-362

74. Rubia K, Smith AB, Woolley J, Nosarti C, Heyman I, Taylor E, Brammer M (2006) Progressive increase of frontostriatal brain activation from childhood to adulthood during event-related tasks of cognitive control. Hum Brain Mapp 27:973-993

75. Sahakian BJ, Coull JT (1993) Tetrahydroaminoacridine (THA) in Alzheimer's disease: an assessment of attentional and mnemonic function using CANTAB. Acta Neurol Scand Suppl 149:29-35

76. Stip E, Sepehry AA, Prouteau A, Briand C, Nicole L, Lalonde P, Lesage A (2005) Cognitive discernible factors between schizophrenia and schizoaffective disorder. Brain Cogn 59:292-295

77. Strauss ME, Reynolds KS, Jayaram G, Tune LE (1990) Effects of anticholinergic medication on memory in schizophrenia. Schizophr Res 3:127-129

78. Stuss DT, Alexander MP (2000) Executive functions and the frontal lobes: a conceptual view. Psychol Res 63:289-298

79. Thaden E, Rhinewine JP, Lencz T, Kester H, Cervellione KL, Henderson I, Roofeh D, Burdick KE, Napolitano B, Cornblatt BA, Kumra S (2006) Early-onset schizophrenia is associated with impaired adolescent development of attentional capacity using the identical pairs continuous performance test. Schizophr Res 81:157-166 
80. Thomsen PH (1996) Schizophrenia with childhood and adolescent onset--a nationwide register-based study. Acta Psychiatr Scand 94:187-193

81. Ueland T, Oie M, Inge LN, Rund BR (2004) Cognitive functioning in adolescents with schizophrenia spectrum disorders. Psychiatry Res 126:229-239

82. Weinberger DR (1987) Implications of normal brain development for the pathogenesis of schizophrenia. Arch Gen Psychiatry 44:660-669

83. Welsh MC, Pennington BF, Groisser DB (1991) A Normative-Developmental Study of Executive Function: A Window on Prefrontal Function in Children. Dev Neuropsychol 7:131-149

84. Werry JS: Child and adolescent (early onset) schizophrenia: a review in light of DSM-III-R (1992) J Autism Dev Disord 22:601-624

85. White T, Ho BC, Ward J, O'Leary D, Andreasen NC (2006) Neuropsychological performance in firstepisode adolescents with schizophrenia: a comparison with first-episode adults and adolescent control subjects. Biol Psychiatry 60:463-471

86. WHO (1992) The ICD-10 Classification of Mental and Behavioural Disorders. Clinical descriptions and diagnostic guidelines. World Health Organization, Geneva

87. WHO (1998) Schedules for Clinical Assessment in Neuropsychiatry Version 2.1. World Health Organization, Division of Mental Health, Geneva

88. Woodward ND, Purdon SE, Meltzer HY, Zald DH (2005) A meta-analysis of neuropsychological change to clozapine, olanzapine, quetiapine, and risperidone in schizophrenia. Int J Neuropsychopharmacol 8:457-472 
89. Zabala A, Rapado M, Arango C, Robles O, de la SE, Gonzalez C, Rodriguez-Sanchez JM, Andres P, Mayoral M, Bombin I (2009) Neuropsychological functioning in early-onset first-episode psychosis: comparison of diagnostic subgroups. Eur Arch Psychiatry Clin Neurosci doi: 10.1007/s00406-009-0046-9

Table 1

Demographic and clinical characteristics for patients with EOS or EOP and controls

\begin{tabular}{|c|c|c|c|c|}
\hline & $\begin{array}{l}\text { EOS }(\mathrm{N}= \\
17)\end{array}$ & $\begin{array}{l}\mathrm{EOP}(\mathrm{N}= \\
11)\end{array}$ & $\begin{array}{l}\text { Controls (N } \\
=38)\end{array}$ & $\mathrm{p}^{1}$ \\
\hline $\begin{array}{l}\text { Mean age at baseline } \\
\text { (SD) (years) }\end{array}$ & $15.6(1.6)$ & $15.2(1.5)$ & $15.6(1.8)$ & $.941 / .489$ \\
\hline $\begin{array}{l}\text { Mean age at follow-up } \\
\text { (SD) (years) }\end{array}$ & $21.0(1.5)$ & $20.5(1.5)$ & $21.3(1.9)$ & $.608 / .453$ \\
\hline $\begin{array}{l}\text { Mean follow-up } \\
\text { interval (SD) (years) }\end{array}$ & $5.4(0.5)$ & $5.4(0.4)$ & $5.6(0.3)$ & $.117 / .927$ \\
\hline Gender (female/male) & $8 / 9$ & $6 / 5$ & $22 / 16$ & $.456 / .699$ \\
\hline $\begin{array}{l}\text { Mean education at } \\
\text { baseline }^{2} \text { (years) (SD) }\end{array}$ & $8.2(1.8)$ & $8.1(1.4)$ & $9.2(1.9)$ & $.074 / .882$ \\
\hline \multicolumn{5}{|c|}{ Parental education/occupation $^{3}$} \\
\hline Academic/Bachelor & $23.5 \%$ & $45.5 \%$ & $50.0 \%$ & \\
\hline Expert/Skilled & $58.8 \%$ & $45.5 \%$ & $50.0 \%$ & \\
\hline Unskilled/Unemployed & $17.6 \%$ & $9.1 \%$ & $0.0 \%$ & $.012 / .458$ \\
\hline
\end{tabular}




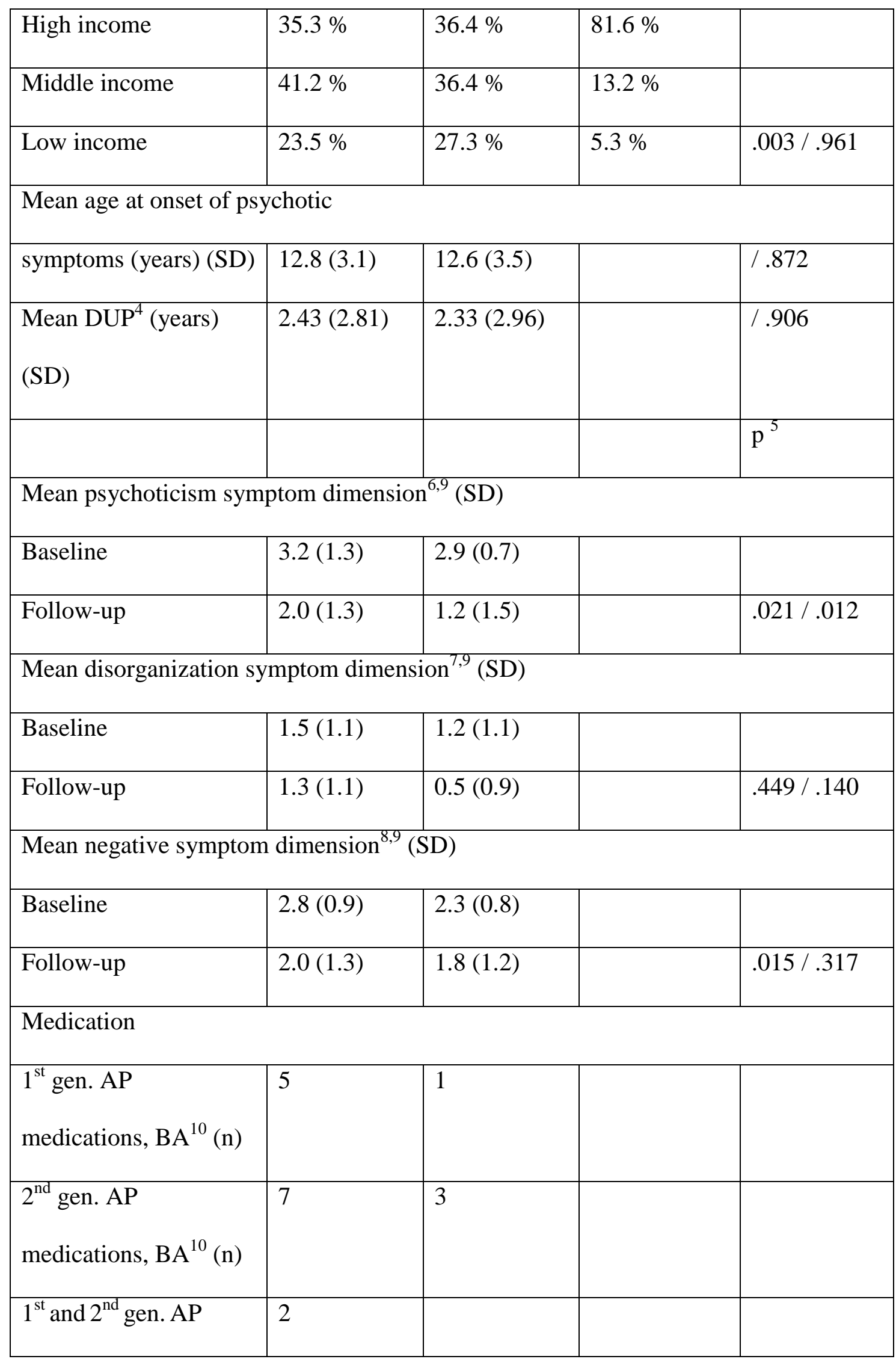




\begin{tabular}{|l|l|l|l|l|}
\hline medications, $\mathrm{BA}^{10}(\mathrm{n})$ & & & & \\
\hline $1^{\text {st }}$ gen. AP & & & & \\
medications, FU & & & \\
\hline $2^{\text {nd }}$ gen. AP & & 0 & & \\
medications, $\mathrm{FU}^{11}(\mathrm{n})$ & & 2 & & \\
\hline $1^{\text {st }}$ and $2^{\text {nd }}$ gen. AP & 3 & 0 & & \\
medications, $\mathrm{FU}^{11}(\mathrm{n})$ & & & & \\
\hline
\end{tabular}

${ }^{1}$ EOS group v. control group / EOS group v. EOP group

${ }^{2}$ The number of years of school attendance; ranges: EOS $(\mathrm{N}=16)$ : 4-10 years, EOP: 6-10 years, controls: $3-12$ years

${ }^{3}$ Frequency within patient and control groups at baseline

${ }^{4}$ The duration (i.e. number of years) of untreated psychosis (DUP)

${ }^{5}$ EOS baseline rating v. EOS follow-up rating / EOP baseline rating v. EOP follow-up rating

${ }^{6}$ ( $\sum$ global rating of severity of hallucinations score; global rating of severity of delusions score)/2

${ }^{7}$ ( $\sum$ global rating of severity of bizarre behaviour score; global rating of positive formal thought disorder score; inappropriate affect item rating score)/3

${ }^{8}\left(\sum\right.$ global rating of affective flattening score; global rating of alogia score; global rating of avolition-apathy score; global rating of anhedonia-asociality score)/4

${ }^{9} 0$ = None; 1 = Questionable; 2 = Mild; 3 = Moderate; 4 = Marked; 5 = Severe

${ }^{10}$ Number of patients treated with first or second generation antipsychotic medications or both types at baseline

${ }^{11}$ Number of patients treated with first or second generation antipsychotic medications or both types at follow-up 
Table 2 Unadjusted and adjusted comparisons of mean change in cognitive domain z-scores between EOS patients and healthy controls

\begin{tabular}{|c|c|c|c|}
\hline & EOS $(\mathrm{N}=17)$ & $\begin{array}{l}\text { Healthy controls } \\
(\mathrm{N}=38)\end{array}$ & $\mathrm{p}^{1}$ \\
\hline Domain & $(\mathrm{N})^{2}$ & $(\mathrm{~N})^{2}$ & $\mathrm{p}^{3}$ \\
\hline \multicolumn{4}{|l|}{ Attention } \\
\hline $\begin{array}{l}\text { Mean change } \\
(\mathrm{SD})[\mathrm{CI}]^{4}\end{array}$ & $\begin{array}{l}\text { (13) } 1.02(2.18)[- \\
0.17 ; 2.21]\end{array}$ & $\begin{array}{l}(38) 0.61(0.87) \\
{[0.33 ; 0.89]}\end{array}$ & .519 \\
\hline $\begin{array}{l}\text { Adjusted mean } \\
\text { change }(\mathrm{CI})^{5}\end{array}$ & $0.18(-0.31 ; 0.67)$ & $0.89(0.62 ; 1.16)$ & .017 \\
\hline \multicolumn{4}{|l|}{ Reaction time } \\
\hline $\begin{array}{l}\text { Mean change } \\
(\mathrm{SD})[\mathrm{CI}]^{4}\end{array}$ & $\begin{array}{l}(15) 0.16(1.45)[- \\
0.57 ; 0.89]\end{array}$ & $\begin{array}{l}(38) 0.17(0.92)[- \\
0.12 ; 0.46]\end{array}$ & .988 \\
\hline $\begin{array}{l}\text { Adjusted mean } \\
\text { change }(\mathrm{CI})^{5}\end{array}$ & $\begin{array}{l}-0.11(-0.60 ; \\
0.39)\end{array}$ & $0.27(-0.03 ; 0.58)$ & .201 \\
\hline \multicolumn{4}{|l|}{ Motor speed } \\
\hline $\begin{array}{l}\text { Mean change } \\
(\mathrm{SD})[\mathrm{CI}]^{4}\end{array}$ & $\begin{array}{l}\text { (15) } 0.65(1.52)[- \\
0.12 ; 1.42]\end{array}$ & $\begin{array}{l}\text { (38) } 0.09(1.12)[- \\
0.27 ; 0.45]\end{array}$ & .147 \\
\hline $\begin{array}{l}\text { Adjusted mean } \\
\text { change }(\mathrm{CI})^{5}\end{array}$ & $\begin{array}{l}-0.01(-0.52 ; \\
0.49)\end{array}$ & $0.35(0.05 ; 0.65)$ & .241 \\
\hline \multicolumn{4}{|c|}{ Speed of processing of executive functions } \\
\hline $\begin{array}{l}\text { Mean change } \\
(\mathrm{SD})[\mathrm{CI}]^{4}\end{array}$ & $\begin{array}{l}\text { (16) } 0.50(1.40)[- \\
0.19 ; 1.19]\end{array}$ & $\begin{array}{l}\text { (38) } 0.47(1.08) \\
{[0.13 ; 0.81]}\end{array}$ & .935 \\
\hline
\end{tabular}




\begin{tabular}{|c|c|c|c|}
\hline $\begin{array}{l}\text { Adjusted mean } \\
\text { change }(\mathrm{CI})^{5}\end{array}$ & $\begin{array}{l}-0.13(-0.75 \\
0.48)\end{array}$ & $\begin{array}{l}\text { (36) 0.61 (0.24; } \\
0.98)\end{array}$ & .065 \\
\hline \multicolumn{4}{|l|}{ Set shifting } \\
\hline $\begin{array}{l}\text { Mean change } \\
(\mathrm{SD})[\mathrm{CI}]^{4}\end{array}$ & $\begin{array}{l}(16) 0.74(1.82)[- \\
0.15 ; 1.63]\end{array}$ & $\begin{array}{l}(38) 0.77(1.16) \\
{[0.40 ; 1.14]}\end{array}$ & .945 \\
\hline $\begin{array}{l}\text { Adjusted mean } \\
\text { change }(\mathrm{CI})^{5}\end{array}$ & $0.16(-0.34 ; 0.66)$ & $1.02(0.70 ; 1.34)$ & .007 \\
\hline \multicolumn{4}{|l|}{ Planning } \\
\hline $\begin{array}{l}\text { Mean change } \\
(\mathrm{SD})[\mathrm{CI}]^{4}\end{array}$ & $\begin{array}{l}(15) 0.50(1.04)[- \\
0.03 ; 1.03]\end{array}$ & $\begin{array}{l}(38) 0.22(0.87)[- \\
0.06 ; 0.50]\end{array}$ & .317 \\
\hline $\begin{array}{l}\text { Adjusted mean } \\
\text { change }(\mathrm{CI})^{5}\end{array}$ & $0.22(-0.23 ; 0.66)$ & $0.33(0.06 ; 0.61)$ & .663 \\
\hline \multicolumn{4}{|c|}{ Working memory } \\
\hline $\begin{array}{l}\text { Mean change } \\
(\mathrm{SD})[\mathrm{CI}]^{4}\end{array}$ & $\begin{array}{l}\text { (9) } 0.72(0.93) \\
{[0.11 ; 1.33]}\end{array}$ & $\begin{array}{l}\text { (38) } 0.05(1.01)[- \\
0.27 ; 0.37]\end{array}$ & .075 \\
\hline $\begin{array}{l}\text { Adjusted mean } \\
\text { change }(\mathrm{CI})^{5}\end{array}$ & $0.27(-0.45 ; 0.98)$ & $0.16(-0.15 ; 0.48)$ & .800 \\
\hline \multicolumn{4}{|l|}{ Verbal memory } \\
\hline $\begin{array}{l}\text { Mean change } \\
(\mathrm{SD})[\mathrm{CI}]^{4}\end{array}$ & $\begin{array}{l}(14)-0.91(2.27) \\
{[-2.10 ; 0.28]}\end{array}$ & $\begin{array}{l}(38)-0.98(1.10) \\
{[-1.33 ;-0.63]}\end{array}$ & .880 \\
\hline $\begin{array}{l}\text { Adjusted mean } \\
\text { change }(\mathrm{CI})^{5}\end{array}$ & $\begin{array}{l}-1.18(-2.06 ;- \\
0.30)\end{array}$ & $\begin{array}{l}-0.89(-1.39 ;- \\
0.38)\end{array}$ & .584 \\
\hline
\end{tabular}

${ }^{1}$ Independent-samples t-tests 
${ }^{2}$ The number of EOS patients and healthy controls, respectively, with that particular domain score at both baseline and follow-up

${ }^{3}$ Analyses of covariance; covariate was the corresponding baseline restandardized domain z-score (baseline domain z-score for Attention and Verbal memory)

${ }^{4} 95 \%$ confidence interval of the unadjusted mean change

${ }^{5} 95 \%$ confidence interval of the adjusted mean change

Figure 1

Retention of patients and healthy controls from baseline to follow-up assessment 


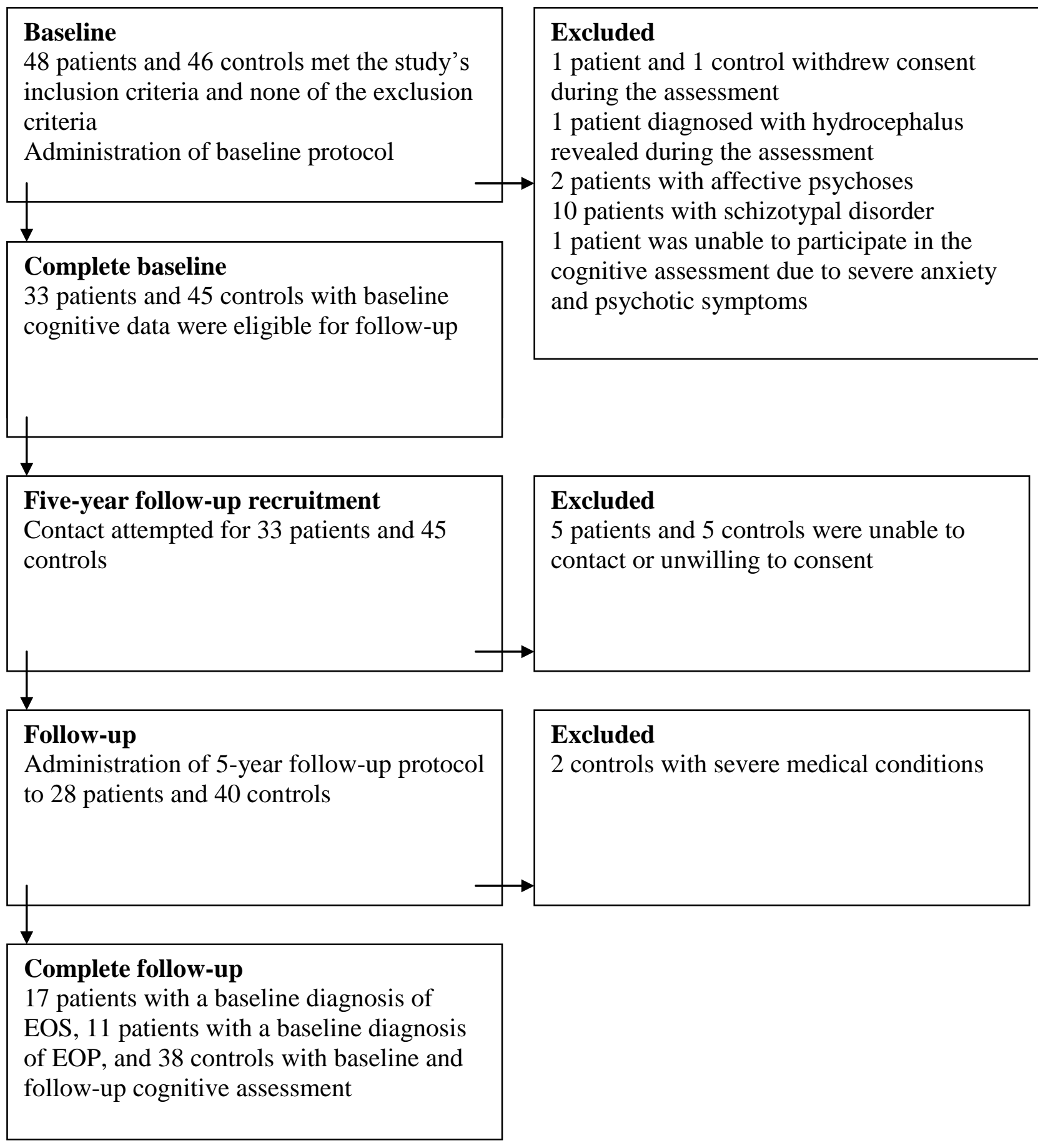

Figure 2

Mean cognitive domain z-scores for EOS and EOP patient groups as well as for the control group at baseline and follow-up 


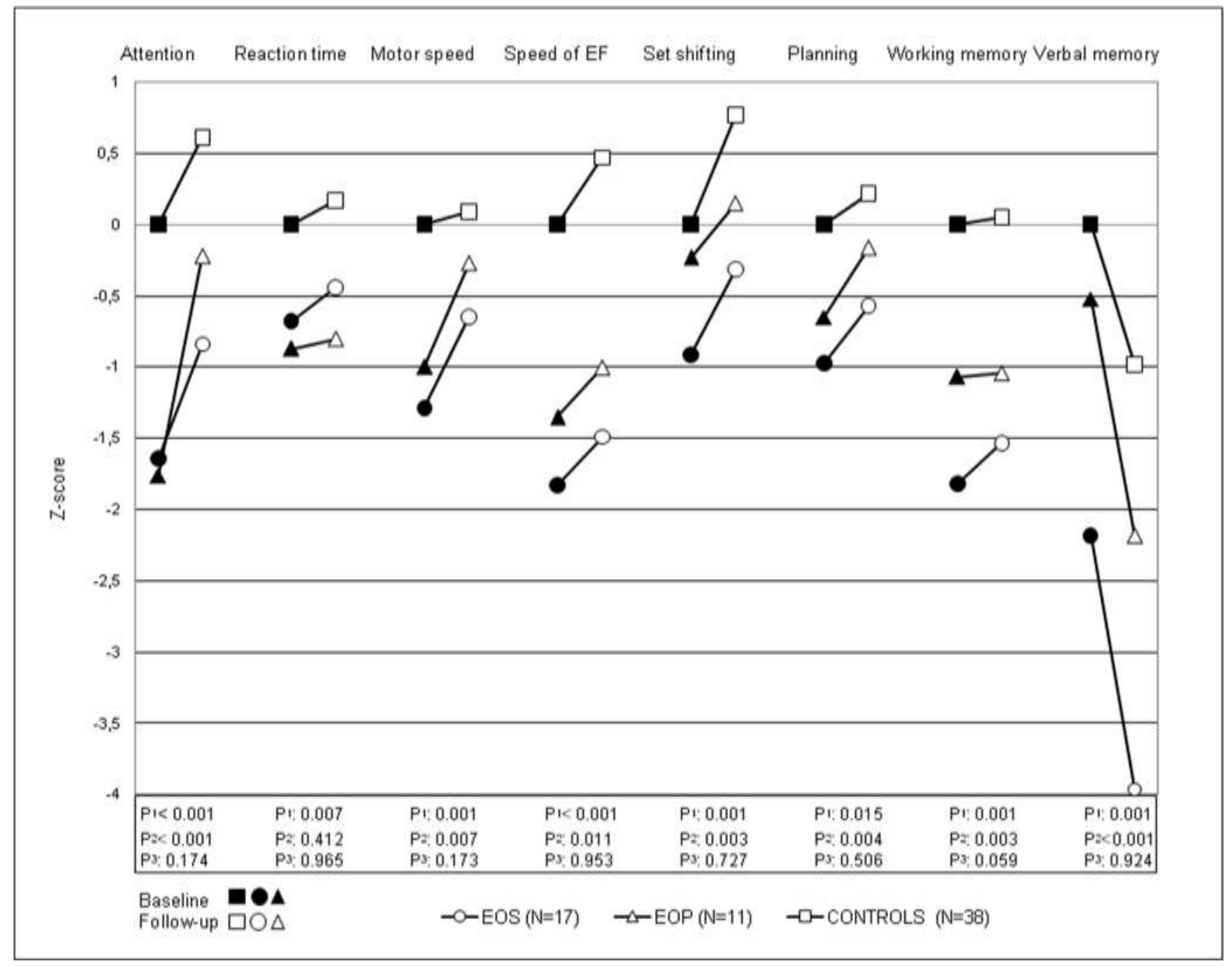

$\mathrm{P}^{1}$ : $\mathrm{P}$-value for repeated measures ANOVA main effect of group

$\mathrm{P}^{2}: \mathrm{P}$-value for repeated measures ANOVA main effect of time

$\mathrm{P}^{3}: \mathrm{P}$-value for repeated measures ANOVA time by group interaction

Attention: Z-score log RVP A`

Reaction time: Restandardized ( $\left(\sum\right.$ z-score log RTI simple reaction time; z-score log RTI fivechoice reaction time)/2)

Motor speed: Restandardized ( $\left(\sum\right.$ z-score log RTI simple movement time; z-score log RTI fivechoice movement time)/2)

Speed of processing of EF: Restandardized ( $\sum$ z-score log Trail B-A; z-score Verbal Fluency (animal); z-score Figural Fluency)/3) 
Set shifting: Restandardized ( $\sum$ z-score log WCST perseverative errors (inclusive perseverative errors according to Nelson's criteria); z-score log IED number of ED errors)/2)

Planning: Restandardized ( $\left(\sum\right.$ z-score SOC problems solved in minimum moves; z-score log SOC mean moves for five-move problems)/2)

Working memory: Restandardized ( $\left(\sum\right.$ z-score SSP; z-score log SWM strategy; z-score log SWM total Between errors; z-score log SWM total Within errors)/4)

Verbal memory: Z-score log Buschke Total Recall 